МОДЕЛИРОВАНИЕ,

МАТЕМАТИЧЕСКИЕ И ДИСТАНЦИОННЫЕ

МЕТОДЫ В ГЕОГРАФИЧЕСКИХ

И ГЕОЭКОЛОГИЧЕСКИХ ИССЛЕДОВАНИЯХ 


\title{
ПРОСТРАНСТВЕННОЕ РАСПРЕДЕЛЕНИЕ АМУРСКОГО ТИГРА В ЗАВИСИМОСТИ ОТ ПЛОТНОСТИ НАСЕЛЕНИЯ И УЯЗВИМОСТИ ОСНОВНЫХ ВИДОВ ЖЕРТВ
}

\author{
Петруненко Ю.К. ${ }^{1}$, Монтгомери Р.А. ${ }^{2,3}$, Серёдкин И.В. ${ }^{\text {, }}$ \\ Заумыслова О.Ю. ${ }^{4}$, Микелл Д.Г. ${ }^{5}$, Макдональд Д.В. ${ }^{3}$ \\ ${ }^{I}$ Тихоокеанский институт географии ДВО РАН, Владивосток, Россия \\ ${ }^{2}$ Университет штата Мичиган, Ист-Лансинг, США \\ ${ }^{3}$ Оксфордский университет, Оксфорд, Великобритания \\ ${ }^{4}$ Сихотэ-Алиинский государственньй природный биосферный заповедник, \\ Терней, Россия \\ ${ }^{5}$ Общество сохранения диких животных, Нью-Йорк, США \\ yurbarius@gmail.com
}

Аннотациия. Теоретические и эмпирические исследования показывают, что распределение хищников в значительной степени определяется доступностью основных видов жертв. Доступность зависит не только от плотности населения животных, но также от их уязвимости, на которую влияет конфигурация атрибутов ландшафта, увеличивающих шанс удачной охоты для хищника. Остается плохо изученным то, как именно пространственные вариации в этих процессах формируют модель поведения хищников в масштабах индивидуального участка. В данном исследовании рассматривалось влияние плотности популяций и уязвимости жертв на использование индивидуального участка амурским тигром Panthera tigris altaica на Дальнем Востоке России в течение 20 снежных сезонов. Всего было построено 80 карт, изображающих предсказание относительной плотности населения видов жертв тигра, как по отдельности, так и для всех видов, объединенных в группу, для каждого снежного сезона года в течение 20 лет исследований. Модель, прогнозирующая относительную уязвимость основных видов жертв в зависимости от ландшафта, в основном включала высоту над уровнем моря, близость к поселкам/сельскохозяйственным районам, крутизну склона, средний уровень покрытия снегом, и близость к ближайшим водотокам. Изюбрь, пятнистый олень и кабан чаще всего добывались в местах с более низкой высотой над уровнем моря в удалении от поселков/сельскохозяйственных районов. Кабан оказался единственным видом, для которого уязвимость увеличивалась в местообитаниях с большей высотой снежного покрова. Обнаружено, что амурский тигр в пределах своего индивидуального участка использует места с наивысшей плотностью населения изюбря Cervus elaphus и кабана Sus scrofa. Важнейшую роль в формировании индивидуального участка тигра играет территория, где изюбрь наиболее уязвим для хищничества, а места с наибольшей плотностью населения изюбря используются на периферии участка обитания хищника. Выявлено две стратегии хищнического поведения тигра. Так как распределение ресурсов в пределах индивидуального участка обитания влияет на выживание и размножение хищника, исследование имеет большое значение не только для более детального понимания взаимоотношений в системе «тигр-жертва», но и для сохранения тигра. 
Ключевые слова: Panthera tigris, амурский тигр, хищник, жертва, участок обитания.

\title{
SPATIAL DISTRIBUTION OF THE AMUR TIGER DEPENDING ON THE DENSITY AND VULNERABILITY OF MAIN PREY SPECIES
}

\author{
Petrunenko Y.K. ${ }^{1}$, Montgomery R.A. ${ }^{2,3}$, Seryodkin I.V. ${ }^{1}$, \\ Zaumyslova O.Y. ${ }^{4}$, Miquelle D.G. ${ }^{5}$, Macdonald D.W. ${ }^{3}$
}

\author{
${ }^{1}$ Pacific Geographical Institute FEB RAS, Vladivostok, Russia \\ ${ }^{2}$ Michigan State University, East Lansing, United States of America \\ ${ }^{3}$ University of Oxford, Oxford, United Kingdom \\ ${ }^{4}$ Sikhote-Alin State Nature Biosphere Reserve, Terney, Primorsky Krai, Russia \\ ${ }^{5}$ Wildlife Conservation Society, New York, United States of America
}

Annotation. Theoretical and empirical studies show that the distribution of predators is largely determined by the availability of the main species of prey. Accessibility depends not only on the population density of animals, but also on their vulnerability, which is affected by the configuration of landscape attributes that increase the chance of successful predator hunting. It remains poorly studied how exactly spatial variations in these processes form a predator behavior model on the scale of an individual site. This study examined the impact of population density and prey vulnerability on the home range use by the Amur tiger Panthera tigris altaica in the Russian Far East for 20 snow seasons. A total of 80 maps were constructed depicting the prediction of the relative population density of tiger prey species, both individually and for all species combined for each snow season for over 20 years of research. The model predicting the relative vulnerability of the main prey species depending on the landscape mainly included altitude, proximity to villages / agricultural areas, slope steepness, average snow cover, and proximity to nearby watercourses. Red deer, sika deer and wild boar were most often killed in places with a lower altitude, away from villages / agricultural areas. The wild boar turned out to be the only species for which vulnerability increased in habitats with greater snow cover. We found that the Amur tiger, within its individual home range, used places with the highest population density of the Manchurian deer Cervus elaphus and wild boar Sus scrofa. The most important role in the formation of tiger individual home range had area where red deer was most vulnerable to predation, and places with the highest density of red deer used at the periphery of individual home ranges. Revealed two strategies of tiger predation. Since the distribution of resources within an individual home range affect the survival and reproduction of the predator, the study is of great importance not only for a more detailed understanding of the relationship in the "tiger-prey" system, but also for the conservation of Amur tiger.

Keywords: Panthera tigris, Amur tiger, predation, prey, home range.

Определение факторов, влияющих на структуру использования территории животными в пределах индивидуальных участков обита- 
ния, дает представление об экологии, выборе ресурсов и численности, что необходимо для ведения природоохранных проектов и грамотного управления популяцией $[16,22]$. Теоретические и эмпирические исследования показывают, что использование хищником мест обитания зависит от распределения и характеристики ресурсов [21], и, в частности, от наличия и доступности жертв [20]. Успешность добычи жертв зависит от распределения/обилия добычи и уязвимости жертвы [11]. Уязвимость определяется индивидуальными характеристиками особи (вид, пол и возраст), а также внешними параметрами ландшафта, повышающими вероятность успешной охоты [11]. Как распределение/обилие, так и уязвимость жертв могут быть связаны с характеристиками ландшафта [8] и могут влиять на структуру обитания хищников, однако важность данных параметров является дискуссионной. Так, гипотеза об обилии жертв прогнозирует, что хищники будут использовать места обитания с наивысшей плотностью населения жертв, в то время как альтернативная гипотеза предполагает, что хищники будут выбирать места обитания, где их добыча является наиболее уязвимой [11].

Значение этих параметров для хищника может зависеть от тактики охоты. Например, охотящиеся из засады и подкрадывающиеся к своей жертве хищники, такие как львы Panthera leo, могут быть наиболее зависимы от параметров ландшафта, обеспечивающих надежное укрытие для успешных охот, в то время как обилие добычи играет второстепенную роль при использовании территории [11]. Особенности ландшафта влияют на вероятность встречи и успех добычи жертвы хищников, активно преследующих свою жертву. Обычно, эти процессы оцениваются с помощью анализа распределения жертв, добытых хищником. Значительная часть этих исследований сосредоточена на том как внешние (например, структура индивидуального участка) и внутренние (например, физическое состояние животного) факторы влияют на выбор стратегии охоты хищника $[8,13]$. Благодаря исследованиям взаимоотношения хищника и жертвы было получено большое количество информации, тем не менее процессы, влияющие на использовании территории в пределах участка обитания, особенно для хищников, ведущих одиночный образ жизни, остаются малоизученными.

Тигр Panthera tigris - самый крупный вид из современных в семействе кошачьих и в своем ареале является доминирующим среди 
всех видов плотоядных. Таким образом, при отсутствии браконьерства главным фактором, ограничивающим рост численности хищника, является плотность популяций его жертв [1]. На первом уровне выбора местообитаний [12] распределение жертв является основным фактором, определяющим ареал амурского тигра $P$. t. altaica, а индивидуальные участки обитания хищника (второй уровень выбора местообитаний [12]), как правило, совпадают с распределением основных видов жертв [1]. Тем не менее, амурские тигры охотятся из засады и подкрадываются к жертве, что позволяет предполагать важное значение пространственной конфигурации мест обитания для повышения успешности охоты [4]. В настоящее время неизвестно, зависит ли третий уровень выбора местообитаний, соответствующий использованию территории внутри индивидуального участка обитания [12] тигров, от плотности населения или уязвимости жертв, или от комбинации этих двух параметров. Кроме того, степень, с которой видовые предпочтения жертв и их уязвимость могут воздействовать на использование индивидуального участка тигром, не анализировалась.

В данной работе были построены пространственные карты плотности популяций и уязвимости жертв с помощью параметров ландшафта за 20 снежных сезонов года, чтобы определить влияние этих параметров на использование территории индивидуального участка амурским тигром на Дальнем Востоке России. Так как плотность населения основного вида жертвы является более сильным фактором, определяющим плотности популяции хищника, чем совокупность плотностей населения всех потенциальных видов жертв [9], а уязвимость жертвы на разных типах ландшафта является видоспецифичной [8], были построены отдельные карты для трех основных видов жертв амурского тигра в снежный период года и карты, объединяющие все три вида.

Характеристика места исследования. Изучение пространственного распределения амурского тигра в зависимости от плотности населения и уязвимости основных видов жертв осуществлялось в 1993-2013 гг. на территории Сихотэ-Алиинского государственного природного биосферного заповедника (4520' с.ш., $136^{\circ} 10^{\prime}$ в.д.), расположенного на территории Приморского края. Район исследования был определен объединенным контуром индивидуальных участков всех тигров, включенных в анализ, построенным методом 95\%-ного фиксированного ядра (общая площадь 1076 км²). Этот шаг гарантиро- 
вал отсутствие расчета плотности населения и уязвимости за пределами индивидуальных участков исследуемых тигров. Доминирующим типом растительности в области исследования является дуб монгольский Quercus mongolica со смешанными хвойно-лиственными лесами, более распространенными на удалении от побережья. Хвойно-лиственные леса в основном состоят из сосны корейской Pinus koraiensis, лиственниц Larix spp., берез Betula spp., ели аянской Picea ajanensis и пихты почкочешуйной Abies nephrolepis. Три основных вида жертв амурского тигра в Сихотэ-Алинском заповеднике - это изюбрь Cervus elaphus, кабан Sus scrofa и пятнистый олень Cervus nippon. Первые два вида являются наиболее предпочитаемыми тигром в заповеднике [14]. Эти три вида составляют около 65-85 \% диеты амурского тигра [14].

Параметры ландиафта. Для изображения атрибутов ландшафта области исследования была разработана геоинформационная система (ГИС) в ArcMap 10.1 и QGIS 2.8.2. ГИС включала высоту над уровнем моря, экспозицию и крутизну склона, пересеченность местности, открытость и средний уровень покрытия снегом. Были также рассчитаны метрические показатели удаления от дороги, поселков/сельскохозяйственных районов, и водотоков. Эти переменные были выбраны из-за того, что они оказывают влияние на использование территории внутри участков обитания тигра, изюбря, кабана и пятнистого оленя на Дальнем Востоке России [18]. Поскольку большая часть территории места исследования покрыта дубовыми лесами, использование типа растительности в качестве параметра оказалось не информативным.

Модели плотности населения жертв. Ежегодные учеты численности животных (включая изюбря, кабана и пятнистого оленя) на территории заповедника проводятся в снежный период года (с ноября по март) по следам на снегу. Эти данные отражают плотность населения разных видов животных с помощью уравнения Формозова, когда известны суточные перемещения животных [3]. Обилие и распространение основных видов жертв амурского тигра в снежный период года существенно не меняется [4]. Таким образом, предполагается, что распределение жертв было относительно постоянным в каждом сезоне, как это было обнаружено в других работах [13].

Для предсказания относительной интенсивности использования среды обитания в каждый из снежных сезонов за период исследования $(n=20$ сезонов) для каждого из трех основных видов жертв были 
построены отрицательные биномиальные функции выбора ресурсов [17]. В результате были получены карты относительной интенсивности использования среды обитания для каждого вида копытных по отдельности, и всех видов, объединенных в одну группу, для каждого снежного сезона за период исследования [18].

Модель уязвимости копытных. Обнаружение жертв амурского тигра осуществлялось во время полевых работ и осмотра мест, на которых задерживались животные, оснащенные радио- и GPSошейниками [14]. Всего за время исследования было обнаружено 247 основных видов жертв тигра (изюбрь, пятнистый олень, кабан). Несмотря на то, что во время исследования было пропущено большое количество жертв тигра, слежение происходило равномерно на всей территории исследований и данные не приурочены к определенному типу ландшафта. Таким образом, в данном исследовании предполагается, что выборка достоверно отражает характеристики ландшафта, связанные с обнаруженными и не обнаруженными местами добычи жертв тигром.

Используя данные о местах нахождения жертв тигра, были построены функции выбора ресурсов для предсказания уязвимости копытных в зависимости от ландшафта (т.е. вероятность добычи животного тигром на участке с данным типом ландшафта) для каждого вида копытных по отдельности и всех видов, объединенных в одну группу [18]. Для построения модели использовался подход «использованное-имеющееся», где места с обнаруженными жертвами тигра представляли «использованное», а ряд случайно распределенных мест по территории исследования представлял «имеющееся» (соотношение 1:4).

Выбор модели и прогностический потенциал. Процедура отбора моделей для оценки плотности населения и уязвимости основных видов жертв была одинакова. Были разработаны все возможные комбинации моделей с атрибутами ландшафта. Для определения наилучших моделей был использован информационный критерий Акаика (AIC) [6]. Коллинеарность была рассмотрена до подгонки моделей. Модели с высокой корреляцией $(|\mathrm{r}|>0,60)$ переменных были удалены из классификации AIC. Модели с $\Delta \mathrm{AIC}<2$ были рассмотрены, в равной степени, и усреднение этих моделей было проведено для получения окончательных оценок параметров [6].

На следующем этапе был оценен прогностический потенциал коэффициентов моделей для оценки плотности населения и уязвимости 
основных видов жертв, используя k-кратную перекрестную проверку достоверности [5]. После данной проверки были построены модели предполагаемой интенсивности использования территории основными видами жертв амурского тигра и предполагаемой относительной уязвимости копытных для всего района исследований.

Модель индивидуального участка амурского тигра. С 1993 по 2013 гг. проводилось слежение за тиграми, оснащенными радио- и GPS-ошейниками, во время которого определялось местоположение животных на территории Сихотэ-Алинского заповедника. Используя точки с местоположением животных, были построены индивидуальные участки амурских тигров с помощью метода распределения использования (utilization distribution, UD) [16, 19]. Для оценки использования местообитаний тигром внутри своего участка обитания были построены пространственно-эксплицитные смешанные модели с линейной регрессией [16].

Выбор модели и величина воздействия параметров. Были использованы два этапа в процессе выбора модели. Во-первых, оценивались все возможные модели, с помощью: 1) основных параметров, предсказывающих относительную интенсивность использования мест обитания основными видами жертв тигра (для каждого сезона), 2) основных параметров, предсказывающих относительную уязвимость жертв, и 3) взаимодействия параметров, предсказывающих относительную интенсивность использования мест обитания основными видами жертв тигра и относительную уязвимость жертв каждого вида или совместно для всех видов. Тестирование эффектов взаимодействия позволило понять, зависело ли использование территории внутри участка обитания в местах с наибольшей уязвимостью жертв от плотности населения жертв на этой территории и наоборот. Далее были разработаны многомерные модели, среди которых была выбрана «начальная модель» [23] на основе значения AIC ( $w$; [6]). На втором этапе выбора модели было проверено можно ли улучшить «начальную модель», используя дополнительные параметры от других основных видов жертв тигра [23]. Таким образом, было многократно увеличено количество переменных от других видов основных жертв тигра, не фигурировавших в стартовой модели. Итоговая модель была оценена с помощью теста отношения правдоподобия [23]. Модель, полученная из этого двухуровневого процесса, считалась самой поддерживаемой моделью, описывающей использование индивидуального участка амурским тигром. 
В исследовании были использованы данные по 18 тиграм, отслеживаемым с помощью радиотелеметрии, в период 1993-2013 гг. В среднем слежение проводилось за 2,2 тиграми за сезон (от 1 до 7 особей) в течение 1,9 последовательных сезонов (1-7 сезонов). В общей сложности, было построено 39 индивидуальных участков тигров за 20 сезонов. Территория исследования была определена объединенным 95 \%-ным распределением использования территории. Изюбрь, кабан и пятнистый олень составили 89 \% (247 из 278) жертв тигра, добытых в снежный период года. Дополнительные виды жертв, добытые тигром на изучаемой территории, включали кабаргу Moschus moschiferus, сибирскую косулю Capreolus pygargus, бурого медведя Ursus arctos, енотовидную собаку Nyctereutes procyonoides и азиатского барсука Meles leucurus. Среди трех основных видов жертв тигра изюбрь составил $43 \%(n=107)$, кабан $-38 \%(n=94)$, пятнистый олень - $19 \%(n=46)$.

Всего было построено 80 карт, изображающих предсказание относительной плотности населения видов жертв тигра, как по отдельности, так и для всех видов, объединенных в группу, для каждого снежного сезона года в течение 20 лет исследований.

Модель, прогнозирующая относительную уязвимость основных видов жертв в зависимости от ландшафта, в основном включала высоту над уровнем моря, близость к поселкам/сельскохозяйственным районам, крутизну склона, средний уровень покрытия снегом, и близость к ближайшим водотокам. Изюбрь, пятнистый олень и кабан чаще всего добывались в местах с более низкой высотой над уровнем моря в удалении от поселков/сельскохозяйственных районов. Кабан оказался единственным видом, для которого уязвимость увеличивалась в местообитаниях с большей высотой снежного покрова. Экспертиза степени корреляции между этими картами показала, что для всех видов жертв тигра уязвимость была схожей внутри индивидуальных участков тигров $(|\mathrm{r}|=0,60$ для изюбря и кабана, $|\mathrm{r}|=0,66$ для изюбря и пятнистого оленя, и $|\mathrm{r}|=0,60$ для кабана и пятнистого оленя). Тем не менее, карты относительной плотности населения жертв были слабо связаны с картами уязвимости жертв на территории исследований. Пространственная корреляция между картами относительной плотности населения и уязвимости жертв составила $|\mathrm{r}|=0,36$ для изюбря, $|\mathrm{r}|=0,17$ для пятнистого оленя, и $|\mathrm{r}|=0,13$ для кабана.

Процедура выбора модели определила, что «начальная модель» описывающая использование индивидуального участка амурским 
тигром, включала прогнозируемую относительную плотность населения изюбря, прогнозируемую относительную уязвимость изюбря, и взаимодействие относительной плотности населения и относительной уязвимости изюбря. Было выявлено, что включение прогнозируемой относительной плотности населения кабана и пятнистого оленя значительно улучшило модель $\left(x^{2}=109,44, \mathrm{DF}=1, p \leq 0,0001\right)$.

Разработанная модель показала, что амурский тигр более интенсивно использовал территорию с более высокой прогнозируемой относительной плотностью населения кабана. Тем не менее, интенсивность использования местообитания тигром снижалась в местах с более высокой прогнозируемой относительной плотностью населения пятнистого оленя. Также было обнаружено, что на интенсивность использования местообитаний тигром влияло взаимодействие прогнозируемой относительной плотности населения и относительной уязвимости изюбря. В частности, на территории с низкой прогнозируемой относительной плотностью населения изюбря тигры чаще использовали места обитания с высокой прогнозируемой относительной уязвимостью изюбря. Интенсивность использования территории тиграми была выше на участках с низкой прогнозируемой относительной вероятностью уязвимости изюбря, даже если эта территория имела низкую относительную плотность населения изюбря. Местообитания с высокой прогнозируемой относительной плотностью населения изюбря использовались тигром только на периферийных областях индивидуальных участков (> 60 процентилей индивидуального участка).

Анализ данных за 20-летний период показал, что использование территории внутри индивидуального участка амурского тигра зависит как от уязвимости жертв, так и от относительной плотности населения основных видов жертв. В частности, было обнаружено, что тигры чаще использовали территорию своих индивидуальных участков с более высокой относительной плотностью населения изюбря и кабана. Тем не менее, эффект плотности населения изюбря модулировался уязвимостью изюбря, определяемой конфигурацией ландшафта. Эти результаты показывают, что использование местообитаний тигра в масштабах индивидуального участка зависит от пространственного взаимодействия численности основных видов жертв и структуры ландшафта.

Использование индивидуального участка амурским тигром, было связано с основными видами жертв - изюбрем и кабаном, предпочи- 
таемыми хищником [10]. Предполагается, что изюбрь и кабан, составляющие 72\% (201 из 278) от общего количества жертв, использовавшихся в данном исследовании, являются излюбленными для тигра, в связи с оптимальными размерами тела. Изюбрь и кабан крупнейшие копытные (за исключением лося, малочисленного на данной территории), доступные для питания тигра на российском Дальнем Востоке, и эти виды играют центральную роль в поддержании энергетических потребностей хищника $[2,14]$. Кроме того, показатель успешности охоты на кабана в снежный период года довольно высокий [4]. Тем не менее, взаимосвязь между увеличением интенсивности использования местообитаний тигра и концентрацией кабана была на низком уровне, вероятно, из-за того, что кабан имеет наименьшую численность среди трех видов основных жертв тигра в прибрежной зоне Сихотэ-Алинского заповедника [3]. Изюбрь - наиболее многочисленный вид, с плотностью населения в снежный период года на территории исследования 1,5-3 особи на км ${ }^{2}$, т то время как плотность населения кабана $0,1-0,5$ особей на км² [3].

Уязвимость и плотность населения изюбря значительно взаимодействовали в наиболее поддерживаемой модели, объясняющей использование индивидуального участка амурским тигром. Карты уязвимости жертв в зависимости от ландшафта и интенсивности использования среды обитания изюбрем не коррелировали $(|\mathrm{r}|=0,36)$, что говорит о том, что изюбрь не был распространен в местах с высокой вероятностью быть добытым тигром из-за конфигурации ландшафта. Результаты данного исследования показывают, что тигры используют две различные стратегии при использовании территории. Первой стратегией является расположение центра индивидуального участка в местах, где жертва для хищника наиболее уязвима, даже если численность жертв невысока. Этот вывод подтверждается тем, что тигры, как охотящиеся из засады и подкрадывающиеся к жертве хищники, используют структуру ландшафта во время охоты [4, 15]. Второй стратегией является использование мест с наибольшей численностью жертв на периферии индивидуального участка. Это утверждение согласуется с тем, что жертвы крупных размеров определяют распределение и численность популяций тигров на всем ареале [7]. Результаты исследования показывают, что тигры имеют определенную степень пластичности в отношении распределения и уязвимости жертв на уровне индивидуального участка. 
Поскольку ресурсы в пределах участков обитания, по крайней мере частично, определяют выживаемость, приспособляемость и плодовитость тигров, результаты исследования имеют значение не только с точки зрения изучения экологии, но и сохранения тигра. Основными угрозами для благополучия амурского тигра в России являются браконьерство и низкая плотность населения копытных $[1,14]$. Результаты данного исследования показывают, что природоохранные инициативы следует сосредоточить на сохранении и увеличении численности изюбря и кабана в ареале хищника. Кроме того, индивидуальные участки тигров имеют большие размеры и еще больше увеличиваются при низкой плотности населения основных видов жертв. Таким образом, в дополнение к сохранению популяций копытных, необходимо направить усилия на сохранение больших территорий, пригодных для обитания тигра.

\section{Литература}

1. Микелл Д.Дж., Смирнов Е.Н., Меррилл Т.У., Мысленков А.И., Куигли Х.Б., Хорнокер М.Г., Шлейер Б.О. Пространственно-иерархический анализ зависимости амурского тигра от местообитаний и видов-жертв // Тигры Сихотэ-Алинского заповедника: экология и сохранение. Владивосток: ПСП, 2005. С. 132-146.

2. Пикунов Д.Г., Серёдкин И.В., Солкин В.А. Амурский тигр: история изучения, динамика ареала, численности, экология и стратегия охраны. Владивосток: Дальнаука, 2010. $104 \mathrm{c}$.

3. Стивенс Ф.А., Заумыслова О.Ю., Хейвард Г.Д., Микелл Д.Дж. Оценка плотности копытных по данным зимних маршрутных учетов в Сихотэ-Алинском биосферном заповеднике // Тигры Сихотэ-Алинского заповедника: экология и сохранение. Владивосток: ПСП, 2005. С. 97-112.

4. Юдаков А.Г., Николаев И.Г. Зимняя экология амурского тигра. По стационарным наблюдениям 1970-1973, 1996-2010 гг. в западной части Среднего Сихотэ-Алиня. 2-е изд. Владивосток: Дальнаука, 2012. 202 с.

5. Boyce M.S., Vernier P.R., Nielsen S.E., Schmiegelow F.K.A. Evaluating resource selection functions // Ecological Modelling. 2002. V. 157. P. 281-300.

6. Burnham K.P., Anderson D.R. Model selection and multimodel inference: A practical information-theoretic approach. 2nd edition. New York: Springer-Verlag, 2002. 488 p.

7. Carroll C., Miquelle D.G. Spatial viability analysis of Amur tiger Panthera tigris altaica in the Russian Far East: the role of protected areas and landscape matrix in population persistence // Journal of Applied Ecology. 2006. V. 43. P. 1056-1068.

8. Gervasi V., Sand H., Zimmerman B., Mattisson J., Wabakken P., Linnell J.D.C. Decomposing risk: Landscape structure and wolf behavior generate different predation patterns in two sympatric ungulates // Ecological Applications. 2013. V. 23. P. 1722-1734.

9. Hayward M.W., O’Brien J., Kerley G.I.H. Carrying capacity of large African predators: predictions and tests // Biology Conservation. 2007. V. 139. P. 219-229. 
10. Hayward M.W., Jędrzejewski W., Jêdrzejewska B. Prey preferences of the tiger Panthera tigris // Journal of Zoology. 2012. V. 286. P. 221-231.

11. Hopcraft J.G.C., Sinclair A.R.E., Packer C. Planning for success: Serengeti lions seek prey accessibility rather than abundance // Journal of Animal Ecology. 2005. V. 74. P. 559-566.

12. Johnson D.H. The comparison of usage and availability measurements for evaluating resource preference // Ecology. 1980. V. 61. P. 65-71.

13. Kauffman M.J., Varley N., Smith D.W., Stahler D., MacNulty D., Boyce M.S. Landscape heterogeneity shapes predation in a newly restored predator-prey system // Ecology Letters. 2007. V. 10. P. 690-700.

14. Miller C.S., Hebblewhite M., Petrunenko Y.K., Seryodkin I.V., DeCesare N.J., Goodrich J.M., Miquelle D.G. Estimating Amur tiger (Panthera tigris altaica) kill rates and potential consumption rates using global positioning system collars // Journal of Mammalogy. 2013. V. 94. P. 8450-855.

15. Miller C.S., Hebblewhite M., Petrunenko Y.K., Seryodkin I.V., Goodrich J.M., Miquelle D.G. Amur tiger (Panthera tigris altaica) energetic requirements: Implications for conserving wild tigers // Biological Conservation. 2014. V. 170. P. 120-129.

16. Montgomery R.A., Roloff G.J., Millspaugh J.J. Importance of visibility when evaluating animal response to roads. Wildlife Biology. 2012. V. 18. P. 393-405.

17. Nielson R.M., Sawyer H. Estimating resource selection with count data // Ecology and Evolution. 2013. V. 3. P. 2233-2240.

18. Petrunenko Y.K., Montgomery R.A., Seryodkin I.V., Zaumyslova O.Y., Miquelle D.G., Macdonald D.W. Spatial variation in the density and vulnerability of preferred prey in the landscape shape patterns of Amur tiger habitat use // Oikos. 2016. V. 125. P. 66-75.

19. Seryodkin I.V., Paczkowski J., Borisov M.Y., Petrunenko Y.K. Home ranges of brown bears on the Kamchatka peninsula and Sakhalin Island // Contemporary Problems of Ecology. 2017. V. 10. No. 6. P. 599-611.

20. Stephens D. W., Krebs J.R. Foraging Theory. Princeton: Princeton University Press, 1986. 247 p.

21. Valeix M., Hemson G., Loveridge A.J., Mills G., Macdonald D.W. Behavioural adjustments of a large carnivore to access secondary prey in a human-dominated landscape // Journal of Applied Ecology. 2012. V. 49. P. 73-81.

22. Woodroffe R., Ginsberg J.R. Edge effects and the extinction of populations inside protected areas // Science. 1998. V. 280. P. 2126-2128.

23. Zuur A., Ieno E.N., Walker N., Saveliev A.A., Smith G.M. Mixed effects models and extensions in ecology with R. New York: Springer, 2009. 574 p.

\section{References}

1. Miquelle D.G., Smirnov E.N., Merrill T.W., Myslenkov A.I., Quigly H.B., Hornocker M.G., Schleyer B.O. [Spatial distribution analyses of Amur tiger depending on habitats and prey species]. Tigry Sikhote-Alinskogo zapovednika: ecologia i sokhranenie [Tigers of the Sikhote-Alin Reserve: ecology and conservation]. Vladivostok, 2005, pp. 132-146.

2. Pikunov D.G., Seryodkin I.V., Solkin V.A. Amursky tygr: Istorya izucheniy, dinamika areala, chislennosti, ecologia I strategia okhrany [Amur tiger: history of study, 
areal dynamic, abundance, ecology and conservation strategy]. Vladivostok, Dalnauka Publ., 2010. 104 p. (In Russian).

3. Stephens F.A., Zaumyslova O.Y., Heyward G.D., Miquelle D.G. [Ungulates density estimations by winter snow track survey in the Sikhote-Alin Biospher Reserve]. Tigry Sikhote-Alinskogo zapovednika: ecologia i sokhranenie [Tigers of the Sikhote-Alin Reserve: ecology and conservation]. Vladivostok, 2005, pp. 97-112.

4. Yudakov A.G., Nikolaev I.G. Zimnyaya ekologiya amurskogo tigra. Po stacionarnym nablyudeniyam 1970-1973, 1996-2010 gg. v zapadnoj chasti Srednego Sihote-Alinya [Winter Ecology of the Amur Tiger Based Upon Observations in West-Central Skihote-Alin Mountains 1970-1973, 1996-2010]. 2nd Revised Edition. Vladivostok, Dalnauka Publ., 2012. 202 p. (In Russian).

5. Boyce M.S., Vernier P.R., Nielsen S.E., Schmiegelow F.K.A. Evaluating resource selection functions. Ecological Modelling, 2002, vol. 157, pp. 281-300.

6. Burnham K.P., Anderson D.R. Model selection and multimodel inference: A practical information-theoretic approach. 2nd edition. New York, Springer-Verlag, 2002. $488 \mathrm{p}$.

7. Carroll C., Miquelle D.G. Spatial viability analysis of Amur tiger Panthera tigris altaica in the Russian Far East: the role of protected areas and landscape matrix in population persistence. Journal of Applied Ecology, 2006, vol. 43, pp. 1056-1068.

8. Gervasi V., Sand H., Zimmerman B., Mattisson J., Wabakken P., Linnell J.D.C. Decomposing risk: Landscape structure and wolf behavior generate different predation patterns in two sympatric ungulates. Ecological Applications, 2013, vol. 23, pp. 1722-1734.

9. Hayward M.W., O’Brien J., Kerley G.I.H. Carrying capacity of large African predators: predictions and tests. Biology Conservation, 2007, vol. 139, pp. 219-229.

10. Hayward M.W., Jędrzejewski W., Jêdrzejewska B. Prey preferences of the tiger Panthera tigris. Journal of Zoology, 2012, vol. 286, pp. 221-231.

11. Hopcraft J.G.C., Sinclair A.R.E., Packer C. Planning for success: Serengeti lions seek prey accessibility rather than abundance. Journal of Animal Ecology, 2005, vol. 74, pp. 559-566.

12. Johnson D.H. The comparison of usage and availability measurements for evaluating resource preference. Ecology, 1980, vol. 61, pp. 65-71.

13. Kauffman M.J., Varley N., Smith D.W., Stahler D., MacNulty D., Boyce M.S. Landscape heterogeneity shapes predation in a newly restored predator-prey system. Ecology Letters, 2007, vol. 10, pp. 690-700.

14. Miller C.S., Hebblewhite M., Petrunenko Y.K., Seryodkin I.V., DeCesare N.J., Goodrich J.M., Miquelle D.G. Estimating Amur tiger (Panthera tigris altaica) kill rates and potential consumption rates using global positioning system collars. Journal of Mammalogy, 2013, vol. 94, pp. 845-855.

15. Miller C.S., Hebblewhite M., Petrunenko Y.K., Seryodkin I.V., Goodrich J.M., Miquelle D.G. Amur tiger (Panthera tigris altaica) energetic requirements: Implications for conserving wild tigers. Biological Conservation, 2014, vol. 170, pp. 120-129.

16. Montgomery R.A., Roloff G.J., Millspaugh J.J. Importance of visibility when evaluating animal response to roads. Wildlife Biology, 2012, vol. 18, pp. 393-405.

17. Nielson R.M., Sawyer H. Estimating resource selection with count data. Ecology and Evolution, 2013, vol. 3, pp. 2233-2240. 
18. Petrunenko Y.K., Montgomery R.A., Seryodkin I.V., Zaumyslova O.Y., Miquelle D.G., Macdonald D.W. Spatial variation in the density and vulnerability of preferred prey in the landscape shape patterns of Amur tiger habitat use. Oikos, 2016, vol. 125, pp. 66-75.

19. Seryodkin I.V., Paczkowski J., Borisov M.Y., Petrunenko Y.K. Home ranges of brown bears on the Kamchatka peninsula and Sakhalin Island. Contemporary Problems of Ecology, 2017, vol. 10, no. 6, pp. 599-611.

20. Stephens D.W., Krebs J.R. Foraging Theory. Princeton, Princeton University Press, 1986. 247 p.

21. Valeix M., Hemson G., Loveridge A.J., Mills G., Macdonald D.W. Behavioural adjustments of a large carnivore to access secondary prey in a human-dominated landscape. Journal of Applied Ecology, 2012, vol. 49, pp. 73-81.

22. Woodroffe R., Ginsberg J.R. Edge effects and the extinction of populations inside protected areas. Science, 1998, vol. 280, pp. 2126-2128.

23. Zuur A., Ieno E.N., Walker N., Saveliev A.A., Smith G.M. Mixed effects models and extensions in ecology with R. New York, Springer, 2009. 574 p. 